\title{
Recovery from Cardiogenic Shock Complicating Right Ventricular Myocardial Infarction
}

\author{
Maj A Henderson \\ BMedSc, BM, BS, MRCP, RAMC \\ Senior Specialist in Medicine \\ Cambridge Military Hospital
}

SUMMARY: Case report of a man with right ventricular infarction complicated by cardiogenic shock who was successfully managed by volume expansion and afterload reduction without haemodynamic monitoring.

\section{Introduction}

Recently the clinical and haemodynamic complications of predominant right ventricular infarction have become clear ${ }^{1}, 4,5,8$. Although the condition is uncommon its importance lies in the high incidence of cardiogenic shock which in sharp contrast to shock complicating left ventricular infarction, carries a good prognosis. A 60 per cent survival has been reported from a sophisticated cardiac centre 4 where full haemodynamic facilities were available. The case reported here illustrates the typical clinical features of right ventricular infarction and shows a good result is possible using the facilities found in any military hospital.

\section{Case History}

A 51 year old officer was admitted with a 5 hour history of crushing central chest pain. He had a 3 month history of hypertension and was taking Atenolol $100 \mathrm{mg}$ daily which was disconinued on admission. The initial ECG (Fig. I) showed inferoposterior myocardial infarction which was subsequently confirmed by a rise in MB CPK to 110 . A chest $\mathrm{x}$-ray taken soon after admission was normal. After analgesia his blood pressure was $130 / 70$, heart rate $60 \mathrm{~B} / \mathrm{min}$ in sinus rhythm but the jugular venous pressure was raised to $10 \mathrm{~cm}$ and peripheral perfusion as judged by skin temperature and capillary return appeared very poor. Over the next 3 hours he became severely hypotensive (systolic BP $80 \mathrm{mmHg}$ ), bradycardiac (pulse $50 \mathrm{~B} / \mathrm{min}$ sinus rhythm) and oliguric. There was no haemodynamic improvement after adequate acceleration of the heart rate with intravenous atropine. The strongly chronotropic catecholamine dopamine successfully maintained an adequate heart rate but even with doses as high as $15 \mathrm{ug} / \mathrm{kg} / \mathrm{min}$, which was probably sufficient to reverse any residual beta blockade, there was still no improvement in blood pressure, peripheral perfusion or urine flow. Major right ventri-

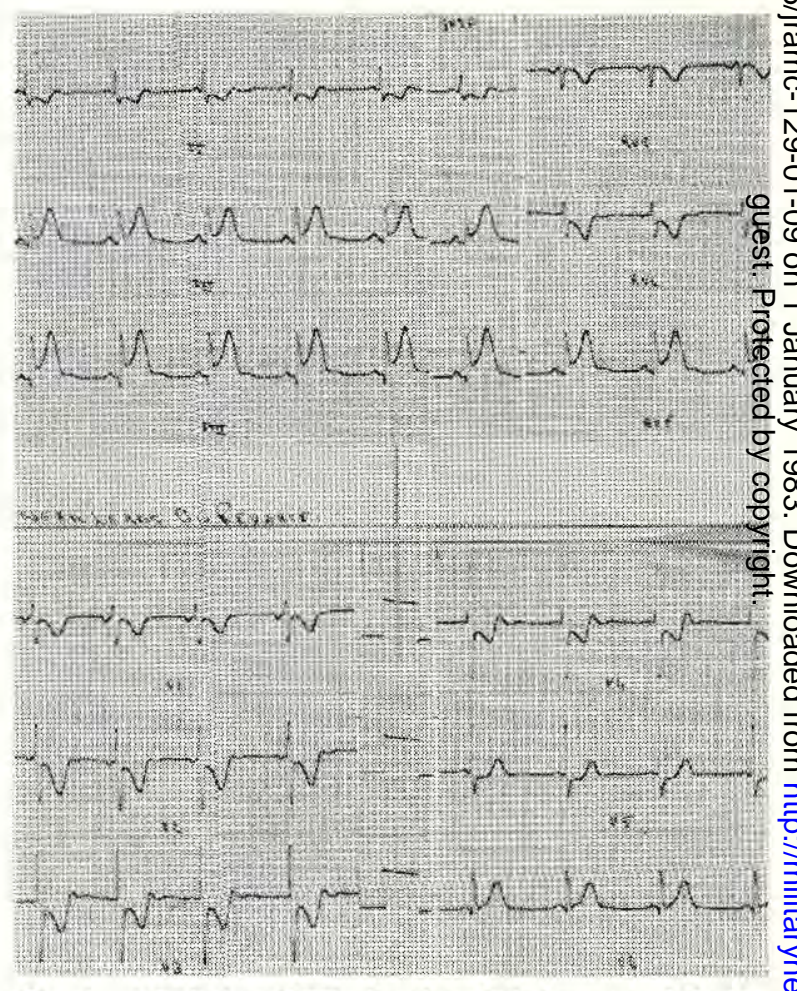

Fig. 1 Admission ECG showing definite acute inferior myocardial infarction with marked anterior ST segment depression, which is thought to be suggestive of posterior damage ${ }^{10}$.

cular infaretion with left ventricular sparing was sus pected on the basis of ECG evidence of inferoposterior myocardial infarction, severe shock, grossly raised JVP and a total absence of pulmonary oedema on the chest $x$-ray. Although facilities for haemodynamic monitoring were not available in view of the immediately life threatening situation a decision 
was made to increase the right heart filling pressures by intravenous colloid while at the same time avoiding the precipitation of pulmonary oedema. An infusion of dextran 70 in $5 \%$ dextrose was commenced at $100 \mathrm{ml} / \mathrm{hr}$. To assess the effect BP, heart rate, hourly urine flow using an indwelling catheter and breathing rate (an acceleration of which gives an early warning of pulmonary oedema) were measured at 10 minute intervals during the infusion. The chest was auscultated every 15 minutes. A further chest $x$-ray taken immediately before commencing the infusion denied pulmonary ocdema. After a total of $250 \mathrm{mls}$ the BP rose to $130 / 80$ without any significant change in heart rate or breathing rate. The JVP was elevated to the angle of the jaw on sitting upright, indicating a substantial elevation of the right heart filling pressures. No further dextran was given even though a third chest $x$-ray still showed clear lungfields, as it was felt the improvement in BP was adequate and that further intravenous dextran without knowledge of the pulmonary artery wedge pressure would be attended by a very high risk of pulmonary oedema. Peripheral perfusion and urine flow however remained poor. To enhance cardiac output an infusion of salbutamol $10 \mathrm{ug} / \mathrm{min}$ was commenced. Peripheral perfusion as judged by skin temperature and capillary return and urine flow increased at the expense of a small fall in BP from 130 to $110 \mathrm{mmHg}$ systolic. Heart rate was unaltered. The dopamine infusion was decremented and stopped after 12 hours without any ill effects. The intravenous salbutamol was continued for a further 24 hours and then replaced by oral salbutamol $4 \mathrm{mg} 4$ times daily. This was conlinued for a week, then decremented and stopped. A later ECG (Fig. II) and a thallium scan confirmed inferoposterior myocardial infarction which was entirely consistent with the diagnosis of major right ventricular infarction. Convalescence was thereafter uneventful and 3 months later formal cardiac assessment was carried out. The patient managed to exercise on the treadmill for $7 \frac{1}{2}$ minutes using the Bruce Protocol, which indicated an excellent functional recovery in view of the gross preceding haemodynamic disturbance.

\section{Discussion}

Cardiogenic shock complicating myocardial infarction carries a mortality approaching $90 \%$ and most of the survivors show severe functional impairment. The vast majority of such patients have suffered greater than $40 \%$ infarction of the left ventricular muscle mass. However, in $30 \%$ of patients with ECG evidence of inferior myocardial infarction, damage to the right ventricle also occurs ${ }^{1,}$, although it usually does not significantly contribute to the clinical picture ${ }^{4,}$. In a small minority right ventricular infarction occurs without significant damage to left ventricle ${ }^{6}, r$. These patients, although uncommon, present with a recognizable clinical picture $^{8}$ of acute inferior or infero-posterior infarction on the ECG, severe haemodynamic impairment or cardiogenic shock, markedly elevated JVP and clear lungfields as judged by chest $x$-rays. At autopsy inferior wall and posterior septal infarction is a universal finding. Shock complicaling left ventricular infarction is different in that the JVP is not so markedly elevated, at least early on in the illness and pulmonary oedema is invariable.

The haemodynamics of predominant right ventricular infarction have been only recently defineds. Typically there is systemic hypotension, low left ventricular end diastolic pressure, low pulmonarke artery wedge pressure, low right ventricular systolic pressure but marked elevation of the right ventricular? diastolic pressure, right atrial pressure and central

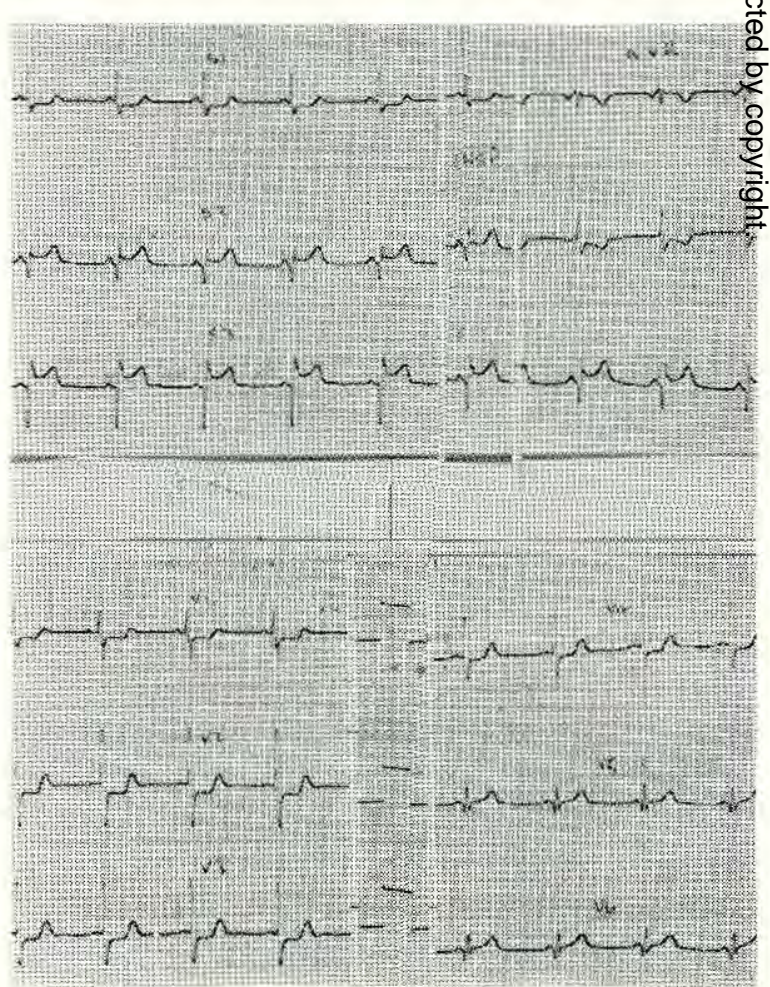

Fig. 2 ECG taken two days later showing definite inferior myocardial infarction and confirming true posterior extension as judged by the abnormally tall $R$ wave in $\mathrm{V} 1$. 
venous pressure. Although in cardiac centres the diagnosis can easily be confirmed by catheterization at the bed side, in many hospitals including army hospitals, reliance must be placed on clinical judgement, ECG and chest x-ray findings. The situation may change in the future as there is some evidence that two dimensional echocardiography reveals diagnostic changes in this condition ${ }^{1,9}$. Management is difficult yet is attended by a gratfying success rate ${ }^{4}$. The best results (60\% survival) have been reported from cardiac centres employing haemodynamic monitoring. Intravenous colloid is infused to elevate the systolic BP and cardiac output (as measured by thermodilution Swan Ganz catheters) while keeping the pulmonary artery wedge pressure below $20 \mathrm{mmHg}$, which effectively prevents the development of pulmonary oedema. Without direct measurements of pulmonary artery wedge pressure it is impossible to precisely judge the fluid requirement which can be small as in the case here, or large (up to 1 litre). Under treatment may well result in death from shock while over-enthusiastic infusion will cause pulmonary oedema. In the case reported relatively crude bed side measurements were employed and successfully allowed adequate elevation of BP without flooding the lungs. It is interesting to note that the dopamine produced litle haemodynamic benefit beyond accelerating the heart rate, and was used predominantly to reverse any remaining beta blockade from the Atenolol. In contrast intravenous salbutamol produced marked improvement. The drug has been shown to produce haemodynamic improvement after major left ventricular infarction by reducing afterload and facilitating left ventricular emptying. In this case the benefit was probably more indirect in that enhanced right ventricular performance probably resulted from reduced resistance to left ventricular filling consequent upon improved left ventricular emptying. It is difficult to know whether the salbutamol reduced pulmonary vascular resistance.

The case illustrates the importance of recognizing right ventricular infarction, a potentially reversible cause of cardiogenic shock which can be successfully managed without formal haemodynamic monitoring. It further reminds us that in the context of acute myocardial infarction an elevated JVP is not necessarily an indication for diuretic therapy, because if right ventricular infarction has occurred, right ventricular performance depends upon a high right sided filling pressure the reduction of which by a diuretic would be attended by marked haemydynamic deterioration.

\section{REFERENCES}

1 Sharpe D $N$, Botvinick E $\mathrm{H}$, Shames D $\mathrm{M}, \stackrel{3}{\gtrless}$ Schiller N B, Massie B M, ChatTerJeE K AND PARMLEY $\mathrm{W}$ W. The non-invasive diagnosis of right $\stackrel{\mathbb{Q}}{\Omega}$ ventricular infarction. Circulation 1978; 57: 483.

2 WAChers F J T, LIE K I, SOHOLE E B, RES J, O SCHOOT J B V D AND DURRER D. Prevalence of right ventricular involvement in inferior wall infarction assessed with myocardial imaging with thallium- $\vec{F}$ 201 and technetium-99m pyrophosphate. $A m J$ of $\stackrel{\mathcal{O}}{9}$ Cardiology 1978; 42: 358.

3 ISNAR J M AND RoBerTs W C. Right ventricular $\frac{\bar{C}}{2}$ infarction complicating left ventricular infarction $\frac{\bar{s}}{\sigma}$ secondary to coronary heart disease. Frequency $\mathbb{Q}$ location, associated findings from analysis of $236 \Omega$ necropsy patients with acute or healed myocardial o infarction. $A m J$ of Cardiology 1978; 42: 885.

4 Lorell B, Lienbach R C, Pohost J O, Gold H K, $\vec{\circ}$ DiNemore R, HutTer A M Jr, Pastore J O AND De $\overrightarrow{\vec{J}}$ SANCTIO R W. Right ventricular infarction. Am $J$ of Cardiology 1979; 43 : 660.

5 CoHN J N. Right ventricular infarction revisited. Am J of Cardiology 1979; 43: 465.

6 Blumgart H L, Schlesinger M J, Davies D. $\stackrel{!}{\sim}$ Studies on the relation of the clinical manifestations 0 of angina pectoris, coronary thrombosis and myo- ${ }^{\circ}$ cardial infarction to the pathologic findings withparticular reference to the significance of the c⿻ lateral circulation. Am Heart J 1940; 19: 1.

7 RoBERTs W C. Coronary arteries in fatal acite myocardial infarction. Circulation 1972; 45: 215. $-\vec{c}$

8 CohN J N, GuiHa N H, Broder M I, Limas C高. Right ventricular infarction clinical and haemorynamic features. Am J of Cardiology 1974; 3⿻ 209.

9 D'ARCY B, NARDA N C. Two dimensional ech- $\overrightarrow{0}$ cardiographic features of right ventricular infarctign. Circulation 1982; 65: 167.

10 Goldbery H L, Borer J S, Jacobstein J G, KLuGón $J$, SCHEIDT $S$ S AND ALONSO D $R$. Anterior Sil segment depression in acute inferior myocardialo infarction; indicator of postereo-lateral infarction. Am J of Cardiology 1982; 48 (6): 1009.

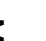

